P0145

\title{
FAÇADE DESIGN OPTIMIZATION BASED ON ENERGY USAGE, GLARE, AND VIEW USING RADIANCE AND NEWHASP
}

\section{Chikako Ohki et al.}

DOI 10.25039/x46.2019.PO145

from

CIE x046:2019

Proceedings

of the

29th CIE SESSION

Washington D.C., USA, June 14 - 22, 2019

(DOI 10.25039/x46.2019)

The paper has been presented at the 29th CIE Session, Washington D.C., USA, June 14-22, 2019. It has not been peer-reviewed by CIE.

(c) CIE 2019

All rights reserved. Unless otherwise specified, no part of this publication may be reproduced or utilized in any form or by any means, electronic or mechanical, including photocopying and microfilm, without permission in writing from CIE Central Bureau at the address below. Any mention of organizations or products does not imply endorsement by the CIE.

This paper is made available open access for individual use. However, in all other cases all rights are reserved unless explicit permission is sought from and given by the CIE.

CIE Central Bureau

Babenbergerstrasse 9

A-1010 Vienna

Austria

Tel.: +4317143187

e-mail: ciecb@cie.co.at

www.cie.co.at 


\title{
FAÇADE DESIGN OPTIMIZATION BASED ON ENERGY USAGE, GLARE, AND VIEW USING RADIANCE AND NEWHASP
}

\author{
Ohki, C. ${ }^{1}$, Okamoto, T. $^{2}$, Tadaki, J. ${ }^{2}$, Ohga, H. ${ }^{1}$, Yoshizawa, N. ${ }^{2}$ \\ ${ }^{1}$ Obayashi Corporation, Tokyo, JAPAN, ${ }^{2}$ Tokyo University of Science, Noda, JAPAN \\ ohki.chikako@obayashi.co.jp
}

DOI 10.25039/x46.2019.PO145

\begin{abstract}
Daylight harvesting is attracting attention not only from the viewpoint of energy saving, but also for improving the health and comfort of people working in buildings. European standards encourage ensuring that daylight is assured, and also provides daylight illumination intensity and aperture target values to obtain sufficient daylight, as well as evaluation criteria for view and glare. Therefore, we combined annual Radiance calculation results using BIM's model with NewHASP in order to develop a simulation model that accurately evaluates annual electric power usage. Our results made it possible to investigate the detailed energy performance of both exterior and interior sun shading devices. Furthermore, the visual environment was evaluated using Radiance, and a multi-objective optimization simulation system was constructed for a composite window system combining vertical louvers for exterior sun shading and venetian blinds for interior sun shading.
\end{abstract}

Keywords: Radiance, NewHASP, Thermal Load Calculation, Energy Simulation, Multi-objective Optimization

\section{Introduction}

In order to achieve ZEB (zero energy buildings), thorough energy-saving practices must be implemented. Efficient daylight harvesting by highly efficient luminaire and various lighting control sensors is thought to be important for energy conservation. Daylight harvesting could potentially reduce the amount of energy usage related to artificial light, but because the introduction of daylight is accompanied by solar heat gain, energy efficiency must be evaluated while accounting for the thermal environment.

Daylight harvesting is attracting attention not only in the field of energy conservation, but also from the viewpoint of the health and comfort. The European Standard EN 17037:2018 encourages building designers to assess and ensure successfully daylit spaces. It also allows building designers and developers to set an ambitions target with respect to daylighting, as well as addressing other issues related to daylight design, such as view out, protection against glare, and exposure to sunlight.

Here, we determined annual heat loads of exterior and interior sun shading (venetian blinds, hereinafter "blinds") via the light environment simulation program Radiance, and the heat load calculation program NewHASP (Nagai and Ohga, 2004). Next, we determined air conditioning and lighting energy usage based upon air conditioning energy usage by the VRF system using the aforementioned heat load and Radiance-obtained data on controlled lighting energy usage via daylight harvesting. The development of the simulation program collaboration has clarified the energy efficiency of rooms with various forms of exterior and interior sun shading devices.

Furthermore, using Radiance, we conducted multi-objective optimization simulations targeting the visual environment and energy usage of composite window systems that utilize vertical louvers as exterior sun shading devices and blinds as interior sun shading devices.

\section{Literature Review}

In past research on window calculations using Radiance, Ohki et al. (2018) used three dimensional models by BIM (Building Information Modeling) to determine controlled lighting energy usage based upon daylight harvesting, and the efficiency of exterior sun shading devices 
using Radiance. The sun shading devices efficiency was input into the heat load calculation program NewHASP (Nagai and Ohga, 2004), and from the resulting of annual heat load, a sequential combined simulation system was developed to determine air conditioning energy usage. Lee et al. (2018) used Radiance in cooperation with EnergyPlus to determine the amount of incident solar radiation for windows caused by direct sunlight.

In past optimization research on exterior and interior sun shading devices, Chutarat and Norford (2002) set the depth and height of the light shelf as variables and optimization calculations to investigate daylight illumination and glare using Radiance. Manzan and Pinto (2009) looked at exterior shading devices, using installation height, length, and distance from the window as variables, and conducted a single objective optimization calculation to minimize energy usage related to air conditioning and lighting; they used Radiance to determine the daylight factor. Azteri et al. (2014) combined roll screens with various types of glass and calculated the PMV (Predicted Mean Vote), DGI (Daylight Glare Index), air conditioning and lighting energy usage using EnergyPlus.

\section{Simulation Flow}

The flow and configuration of the multi-objective optimization simulation model developed here is shown in Figure 1. Direct radiation, diffuse radiation, dimming level, and blind modules from Radiance were utilized; the heat load was determined in NewHASP, and the air conditioning energy usage was determined via the VRF system simulation. The dimming level module was used to find the total lighting energy usage. Radiance was used for both the glare module and view module.

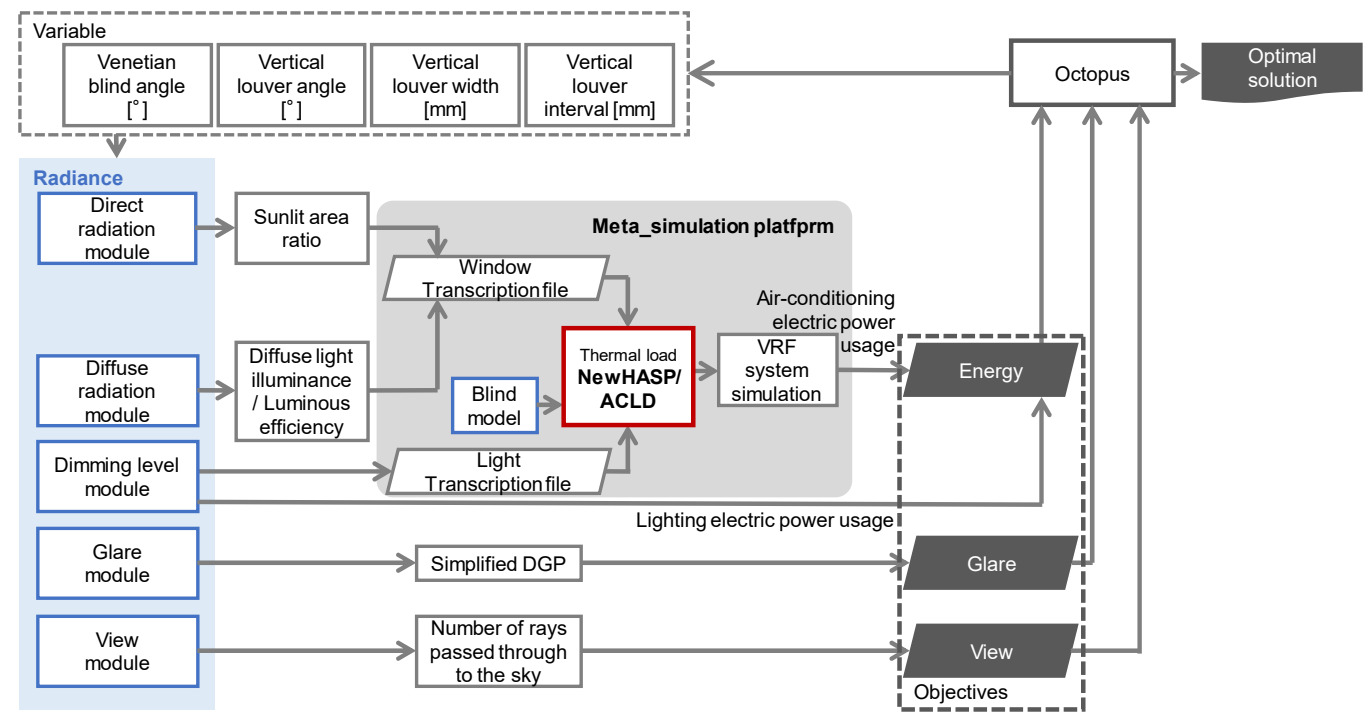

Figure 1 - Configuration and flow of simulation model

\subsection{Radiance Simulations}

\subsubsection{Direct Radiation Module}

To determine energy usage for air conditioning, we separated solar heat gain into three categories (Ohki et al., 2009) for the glass window solar heat gain calculation (Figure 2): (1) the window sunlit area based upon window illuminance determined by Radiance was used in the direct radiation calculation; (2) the illuminance from the sky was determined by Radiance, and used for the diffuse radiation calculation of the sky; (3) the illuminance determined by Radiance was used for the calculation of the diffuse component of solar radiation reflected from the ground and exterior sun shading devices. As a result, diffuse radiation from reflected light caused by exterior sun shading devices, which could not be accounted for using conventional NewHASP, could be correctly calculated. Glass window solar heat gain features detailed by conventional NewHASP and Radiance are shown in Table 1. 
For the calculation of the window sunlit area, direct solar radiation was set as the only light source; window illuminance was calculated Note 1) with ground and exterior sun shading devices reflectance set at $0 \%$; the area ratio of illuminance greater than 0 was calculated.

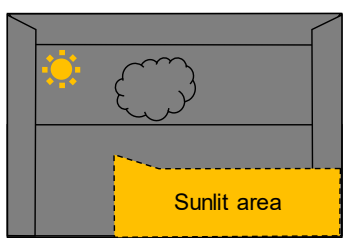

Sunlit area

( Direct solar radiation )

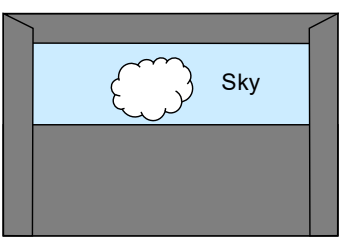

Sky area

( Diffuse solar radiation )

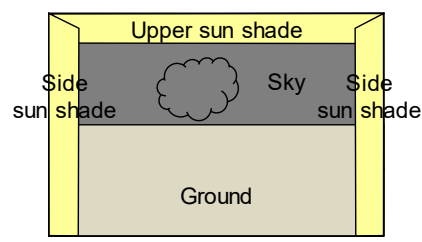

Reflection area

( Diffuse solar radiation )

Figure 2 - Window solar radiation separation method

Table 1 - Features of NewHASP and Radiance

\begin{tabular}{|c|l|l|}
\hline & \multicolumn{1}{|c|}{ NewHASP } & \multicolumn{1}{c|}{ Radiance } \\
\hline Sunlit area & $\begin{array}{l}\text { Wall of adjacent building exists } \\
\text { infinitely in horizontal direction } \\
\text { Assume exterior sun shading } \\
\text { devices orthogonal to window }\end{array}$ & $\begin{array}{l}\text { No constraint on shape of } \\
\text { exterior sun shading devices } \\
\text { No constraint on shape of } \\
\text { adjacent buildings wall }\end{array}$ \\
\hline $\begin{array}{c}\text { Reflection from exterior } \\
\text { sun shading devices } \\
\text { and wall of adjacent } \\
\text { buildings }\end{array}$ & Not considered & Considered \\
\hline Sky & Uniform sky & Sky with luminance distribution \\
\hline
\end{tabular}

\subsubsection{Diffuse Radiation Module}

For window illuminance based on sky light, sky light was set as the only light source; the average window illuminance was determined Note 1) with ground and exterior sun shade reflectance set at $0 \%$; the average was divided by hourly luminous efficacy $\eta_{-} e p w$ on EnergyPlus Weather data and set as the diffuse radiation.

For window illuminance based on reflected light from ground and exterior sun shades, direct sunlight and sky light were set as the light sources; two illuminances were determined Note 1) when ground and exterior sun shade reflectance were input, and when these reflectance were set at $0 \%$. The difference of two illuminance was calculated as the illuminance based upon reflection from the ground and exterior sun shading devices. This illuminance was divided by hourly luminous efficacy $\eta_{-} e p w$ and calculated the diffuse radiation based on reflected light from ground and exterior sun shading devices.

\subsubsection{Dimming Level Module}

The annual light dimming level detected by illuminance sensors was determined by considering the effects of daylight (Yoshizawa et al., 2019) Note 1). The cone-shaped illuminance sensors (open at the bottom; 0\% reflectance; Figure 3 ) were installed in the ceiling and positioned to produce the illumination detection area (detection range of sensor $64^{\circ}$ ) shown in Figure 3 . The dimming level was used light heat gain of NewHASP and lighting energy usage calculations.

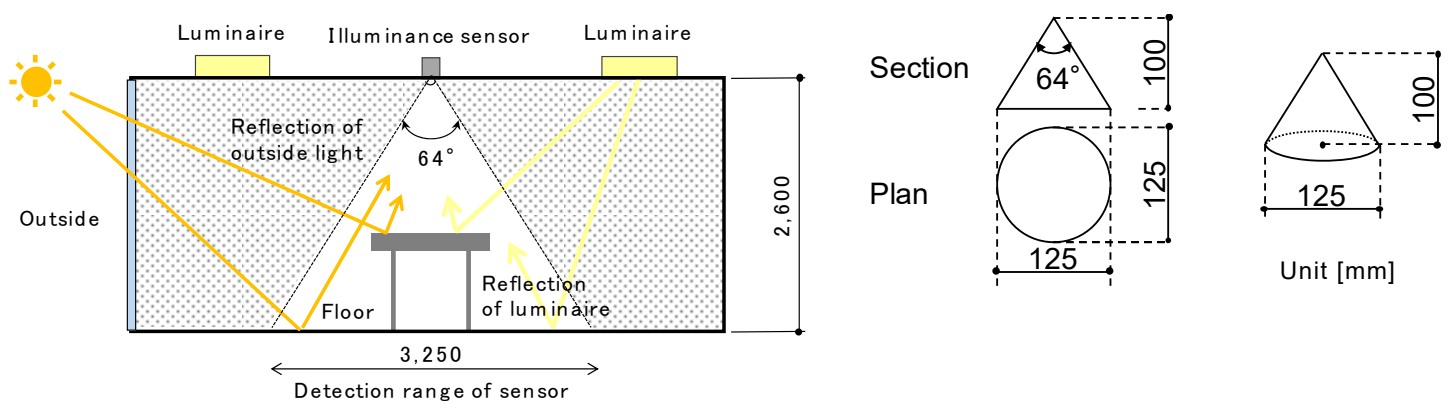

Figure 3 - Illuminance sensor detection range and Detail of sensor shape 


\subsubsection{Glare Module}

We evaluated daylight glare for comfort of office workers. The glare index includes the Predicted Glare Sensation Vote (PGSV; Architectural Institute of Japan, 2018) and Daylight Glare Probability (DGP; Wienold, 2009). PGSV predicts and evaluates daylight glare discomfort, and is suitable for assessment of window sizes in open-plan Japanese offices (Architectural Institute of Japan, 2018). DGP represents the percentage of people who feel discomfort by daylight; simplified DGP can provide a simple evaluation by vertical illuminance, and suitable for annual evaluations of facades and sun shading devices (Wienold, 2009). Here, an annual calculation of vertical illuminance from a point within a room was calculated using Radiance, and the glare was evaluated using simplified DGP.

\subsubsection{View Module}

Using Radiance's rtrace command, light rays of line-of-sight vectors from various viewpoints were traced (Figure 4), and the number of rays that reached the sky, ground, or sun shading devices were output pixel-by-pixel. An equisolid angle projection, in which the appearance size and proportionate number of pixels are equal, was utilized. Formula (1) was used to calculate the ratio of rays that reach the sky and as a view index.

$$
\mathrm{V}=\frac{\mathrm{N}}{\pi \mathrm{R}^{2}} \times 100
$$

where

$$
\begin{array}{ll}
\mathrm{V} & \text { View ratio (\%) } \\
\mathrm{N} & \text { Number of pixels with elements of sky } \\
\mathrm{R} & \text { Radius on projection drawings (pixels) }
\end{array}
$$

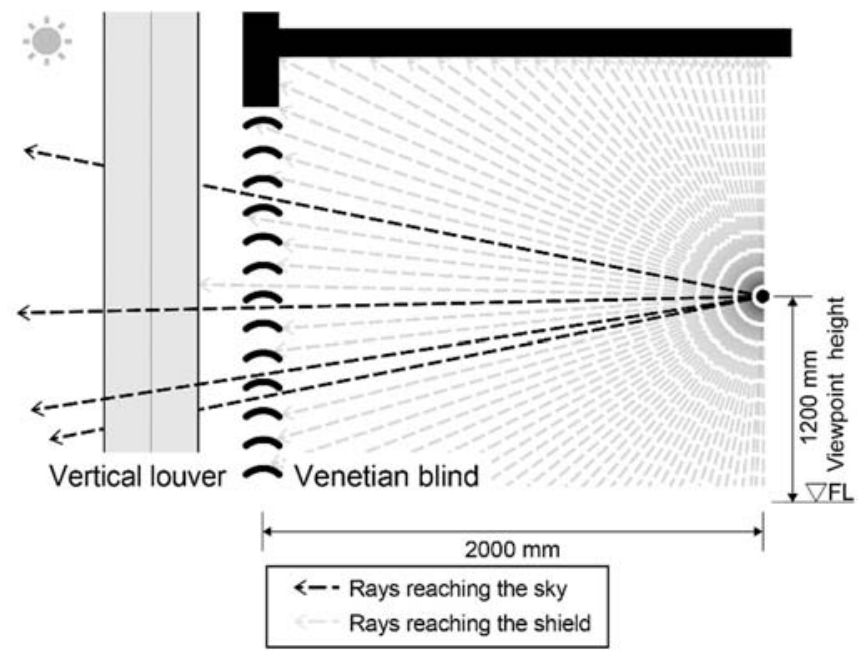

Figure 4 - Radiance ray tracing

In this study, the viewpoint coordinates were set to $2 \mathrm{~m}$ interior the room (from the centre of the window) and at a height of $1.2 \mathrm{~m}$; the line-of-sight faced the window. The resolution was set to ensure that the light rays could pass through the width of the blinds.

\subsubsection{Blind Module}

Direct sunlight was applied to blind profile angles set at $5^{\circ}$ intervals from $0^{\circ}-85^{\circ}$ (Figure 5 ). Radiant flux calculations for slats with different angles $\left(-75^{\circ},-45^{\circ}, 0^{\circ}, 45^{\circ}\right.$, and $\left.75^{\circ}\right)$ were determined using Radiance, and the transmittance $T$ and reflectance $\rho$ of each blind were identified (Ohga et al. 2017). The relationships between profile angle $\varphi$ and the transmittance and reflectance of each slat angle were approximated using the equation of the fifth power of $\cos \varphi$; by displaying those approximate equation factors in approximate equations for slat angle $\theta$, the transmittance function $T(\varphi, \theta)$ and reflectance function $\rho(\varphi, \theta)$ were determined. The transmittance features produced by these functions are shown in Figure 6. 


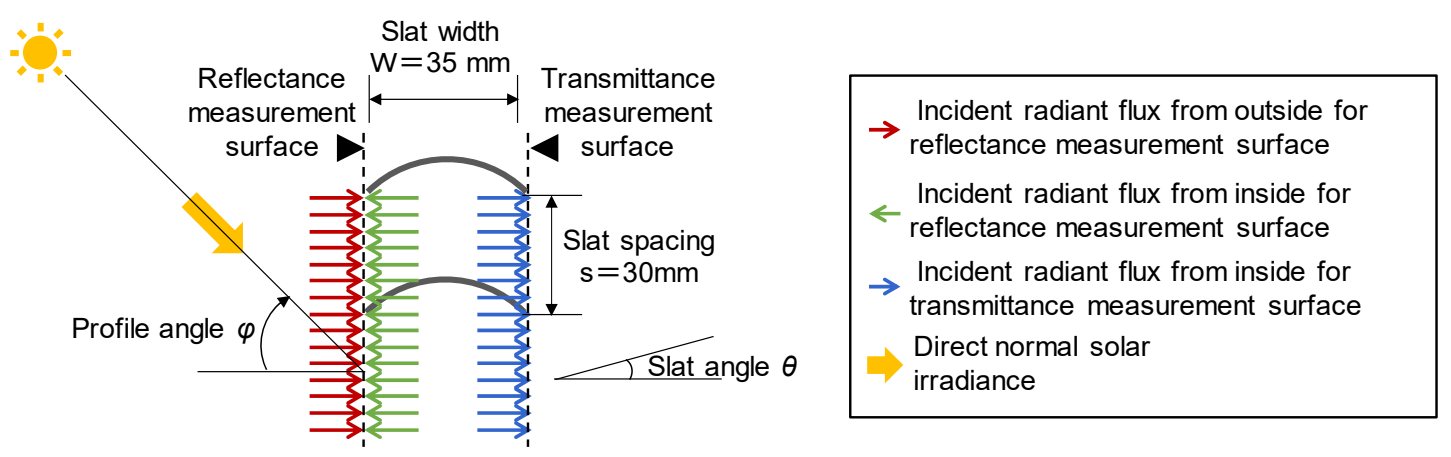

Figure 5 - Radiance simulation blind function: $\tau(\varphi, \theta), \rho(\varphi, \theta)$
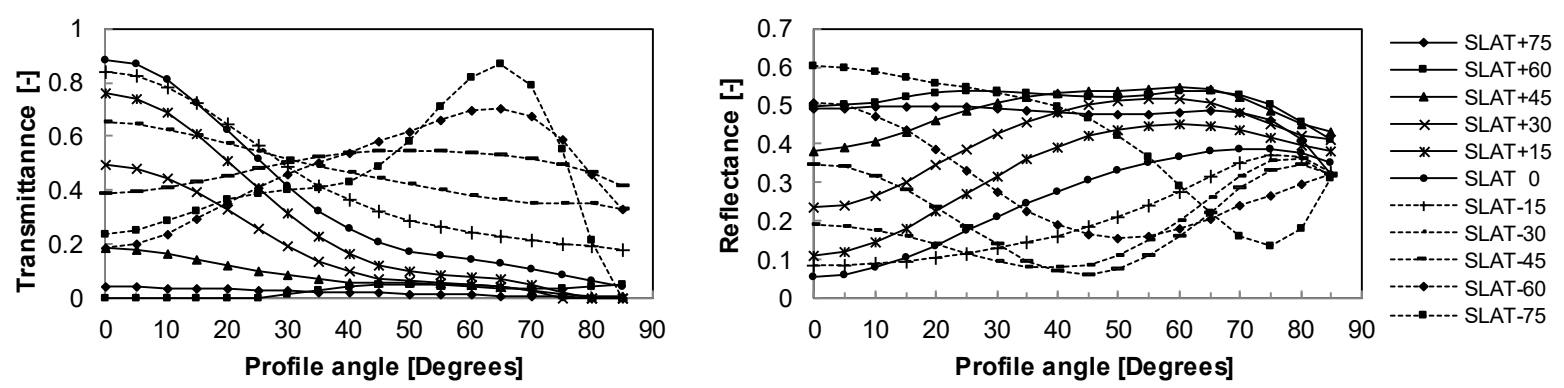

Figure 6 - Blind transmittance function: $T(\varphi, \theta), \rho(\varphi, \theta)$

\subsection{NewHASP Simulations}

NewHASP (the Society of Heating, Air Conditioning and Sanitary Engineers of Japan) is widely used in academic research and design practice in Japan. It has functions to estimate the effect of daylight harvesting, but the algorithm is simple and cannot take into consideration complex daylight harvesting control systems. After incorporating Radiance calculation results into conventional NewHASP, we determined the annual heat load by creating a meta-simulation using NewHASP as the core (Ohga, 2016; Ohga et al., 2017a, 2017b; Ohki et al., 2017), and then evaluated energy efficiency. To minimize changes within each program, data exchange took place during batch processing with transcription files from both simulations were used as intermediaries, preserving the independence of each program.

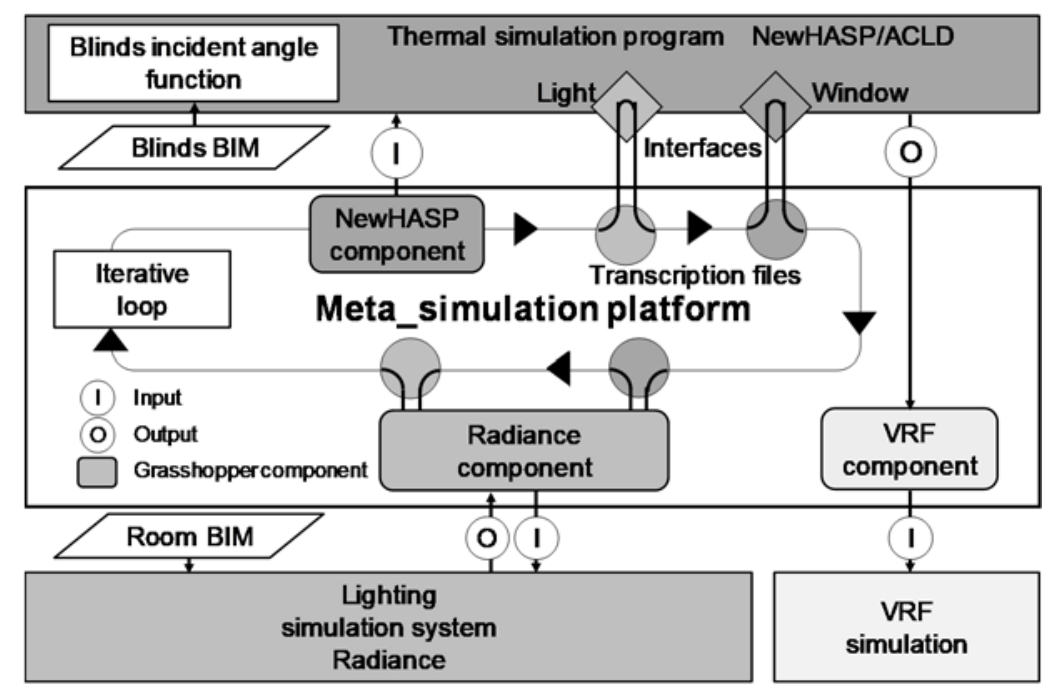

Figure 7 - Meta-simulation platform 


\subsection{VRF System Simulation}

Using the periodic heat load from NewHASP (Public Architectural Institute of Japan, 2015), we created an input/output ratio formula for outside temperature and indoor temperature in order to determine energy usage for air conditioning. Formula (2) took the periodic input/output ratio of outside temperature to indoor absorbed air temperature and the partial load, corrected the rated COP (Coefficient Of Performance) for the VRF system, and calculated the heat load.

$$
C O P_{S}=C O P \times \frac{O_{o}}{I_{o}} \times \frac{O_{i}}{I_{i}}
$$

where
$\mathrm{COP}_{S} \quad$ Operating COP
COP Rated COP
$I_{o} \quad$ Outside Temperature (DB) Input/Output Ratio
$O_{o} \quad$ Outside Temperature (WB) Input/Output Ratio
$I_{i} \quad$ Indoor Absorbed Air Temperature (WB) Input/Output Ratio
$O_{i} \quad$ Indoor Absorbed Air Temperature (DB) Input/Output Ratio

\subsection{Multi-Objective Optimization}

We used the graphical algorithm editor Grasshopperto evaluate air conditioning/lighting energy, glare, and view. The optimization analysis was conducted using Grasshopper's plug-in software OCTOPUS, which can handle multi-objective genetic algorithms. Four parameters related to exterior and interior sun shading devices were changed and evaluated based upon three objectives.

The total air conditioning/lighting energy usage was evaluated by combining the air conditioning energy usage from the VRF system simulation with the lighting density and the lighting energy usage determined by the dimming levels from the dimming level module. Glare was evaluated using the glare module the ratio of value at certain points in a room that exceeded the simplified DGP threshold. The view was evaluated using the view module the ratio of viewable sky at certain points in a room.

\section{Simulation Examples}

\subsection{Simulation Target: Building}

We targeted the building shown in Figure 8 and evaluated its exterior / interior sun shading devices energy usage, glare, and view. We assumed LED lighting at a rated luminous flux of $3,334 \mathrm{Im}$ (luminous efficacy $100 \mathrm{Im} / \mathrm{W}$ ) and set 24 luminaires by $600 \mathrm{~mm}$ square grid on the ceiling, to be $1,000 \mathrm{~lx}$ at maximum dimming levels; we controlled the dimming levels so that the average desktop illumination by daylight was 750lx (Yoshizawa et al., 2018). The illuminance sensor was placed in the centre of the room, and the glare and view rating were placed 2,000$\mathrm{mm}$ from the façade. Calculation conditions are shown in Table 2.

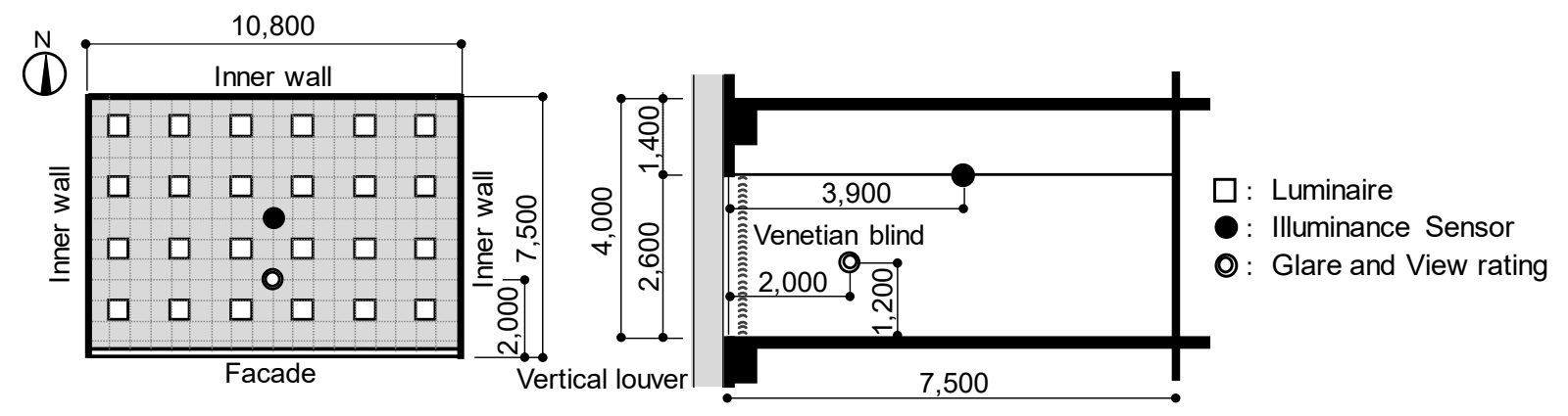

Figure 8 - Room plan and section 


\subsection{Exterior / Interior Sun shading devices}

The exterior / interior sun shade forms targeted by the simulation are shown in Figure 9 and Figure 10. The exterior sun shading devices were the vertical louver, and the following variables were arbitrarily changed: angle from $0^{\circ}-180^{\circ}$, width from $220-550 \mathrm{~mm}$, and spacing from 1,000 $2,000 \mathrm{~mm}$. The interior sun shading devices were the blind, and the angle was changed from $0^{\circ}-70^{\circ}$ at $10^{\circ}$ intervals.

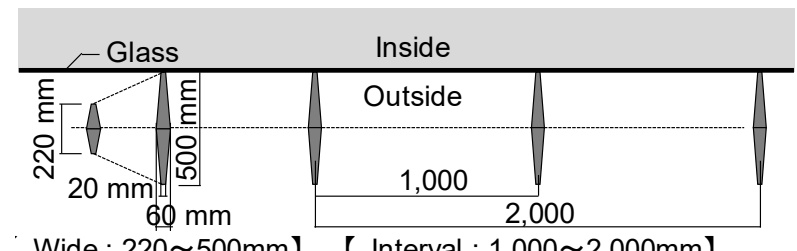

Wide : 220 500mm 】 【Interval : 1,000 2,000mm】

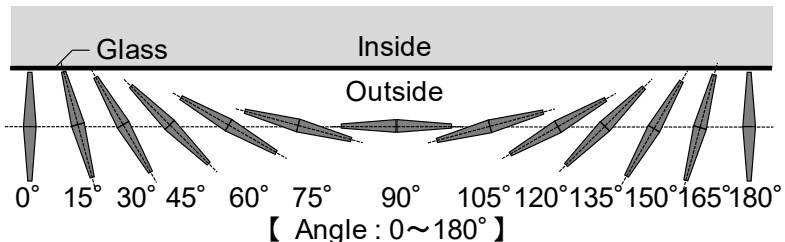

【 Angle: $0 \sim 180^{\circ}$ 】

Figure 9 - Detail of vertical louver

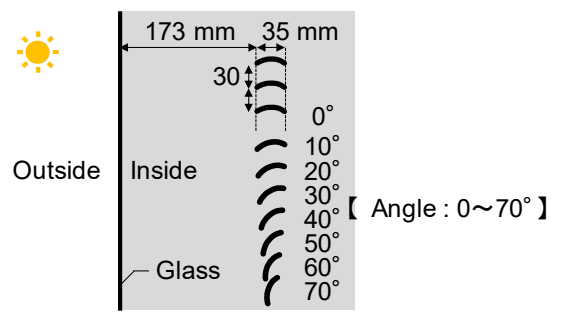

Unit [mm]

Figure 10 - Detail of Venetian blind

Table 2 - Calculation conditions

\begin{tabular}{|c|c|c|}
\hline Building model & $\begin{array}{l}\text { Room usage } \\
\text { Orientation } \\
\text { Floor space } \\
\text { Ceiling Height } \\
\text { Floor above ground level }\end{array}$ & $\begin{array}{l}\text { Office } \\
\text { Facing south } \\
81 \mathrm{~m}^{2} \\
2.6 \mathrm{~m} \\
25.2 \mathrm{~m}\end{array}$ \\
\hline Weather data & Tokyo Hyakuri & $\begin{array}{l}\text { EPW data (Weather Data for } \\
\text { EnergyPlus) }\end{array}$ \\
\hline $\begin{array}{l}\text { Condition of indoor temperature } \\
\text { and humidity }\end{array}$ & $\begin{array}{l}\text { Summer: } 26^{\circ} \mathrm{C}, 60 \% \text { or less } \\
\text { Winter/intermediate period: } 22^{\circ}-26\end{array}$ & $\mathrm{C}, 40 \%$ or more \\
\hline Internal heat and others & $\begin{array}{l}\text { Personnel density } \\
\text { Lighting density } \\
\text { Equipment density (sensible heat } \\
\text { only) }\end{array}$ & $\begin{array}{l}0.1 \text { persons } / \mathrm{m}^{2} \\
9.8 \mathrm{~W} / \mathrm{m}^{2} \\
12 \mathrm{~W} / \mathrm{m}^{2}\end{array}$ \\
\hline Glass & $\begin{array}{l}\text { Side continuous windows } \\
\text { Ordinary transparent single plate } \\
\text { Transmittance }\end{array}$ & $\begin{array}{l}28 \mathrm{~m}^{2} \\
8 \mathrm{~mm} \\
87 \%\end{array}$ \\
\hline Outer wall & $\begin{array}{l}\text { South } \\
\text { Reflectance }\end{array}$ & $\begin{array}{l}15.1 \mathrm{~m}^{2} \\
50 \%\end{array}$ \\
\hline Inner wall & Reflectance & Fully insulated wall \\
\hline Floor & Reflectance & $20 \%$ \\
\hline Ceiling & Reflectance & $70 \%$ \\
\hline Ground & Reflectance & $20 \%$ \\
\hline Exterior sun shading devices & Reflectance & $70 \%$ \\
\hline VRF system COP & \multicolumn{2}{|l|}{ Cooling: 3.36 , Heating: 3.77} \\
\hline Glare & \multicolumn{2}{|c|}{ Simplified DGP threshold: 2.0, Viewpoint height: $F L+1,200 \mathrm{~mm}$} \\
\hline View & \multicolumn{2}{|l|}{ Viewpoint height: $F L+1,200 \mathrm{~mm}$} \\
\hline
\end{tabular}




\subsection{Parametric Simulation Results}

To investigate the behaviour of the basic parameters in the multi-objective optimization simulation, the annual air conditioning/lighting energy usage, glare, and view for exterior I interior sun shading devices was calculated (Table 3; Figure 11-Figure 13).

Table 3 - Simulation cases

\begin{tabular}{|c|c|c|c|c|}
\hline Case & $\begin{array}{c}\text { Venetian blind angle } \\
{\left[{ }^{\circ}\right]}\end{array}$ & $\begin{array}{c}\text { Vertical louver angle } \\
{\left[{ }^{\circ}\right]}\end{array}$ & $\begin{array}{c}\text { Vertical louver width } \\
{[\mathrm{mm}]}\end{array}$ & $\begin{array}{c}\text { Vertical louver interval } \\
{[\mathrm{mm}]}\end{array}$ \\
\hline $\mathrm{a}$ & 0 & 0 & 220 & 1,000 \\
\hline $\mathrm{b}$ & 0 & 0 & 220 & 2,000 \\
\hline $\mathrm{c}$ & 0 & 0 & 500 & 1,000 \\
\hline $\mathrm{d}$ & 0 & 0 & 500 & 2,000 \\
\hline $\mathrm{e}$ & 0 & 90 & 220 & 1,000 \\
\hline $\mathrm{f}$ & 0 & 90 & 220 & 1,000 \\
\hline $\mathrm{g}$ & 0 & 90 & 500 & 2,000 \\
\hline $\mathrm{h}$ & 0 & 90 & 500 & 1,000 \\
\hline $\mathrm{i}$ & 70 & 0 & 220 & 2,000 \\
\hline $\mathrm{j}$ & 70 & 0 & 220 & 1,000 \\
\hline $\mathrm{k}$ & 70 & 0 & 500 & 2,000 \\
\hline $\mathrm{I}$ & 70 & 0 & 500 & 1,000 \\
\hline $\mathrm{m}$ & 70 & 90 & 220 & 2,000 \\
\hline $\mathrm{n}$ & 70 & 90 & 220 & 1,000 \\
\hline $\mathrm{o}$ & 70 & 90 & 500 & 2,000 \\
\hline $\mathrm{p}$ & 70 & 90 & 500 & \\
\hline
\end{tabular}

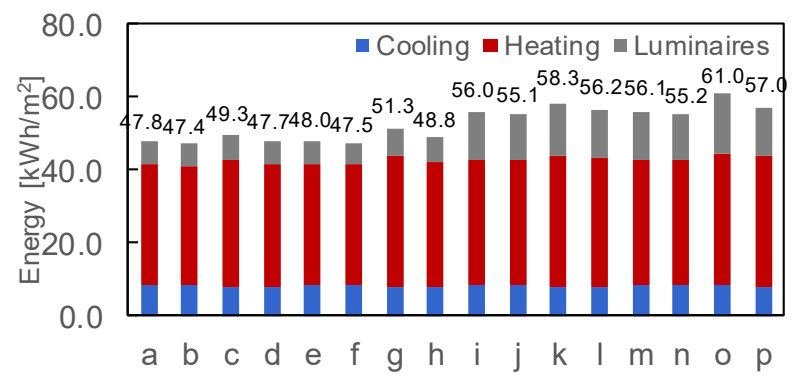

Figure 11 - Annual electric power usage

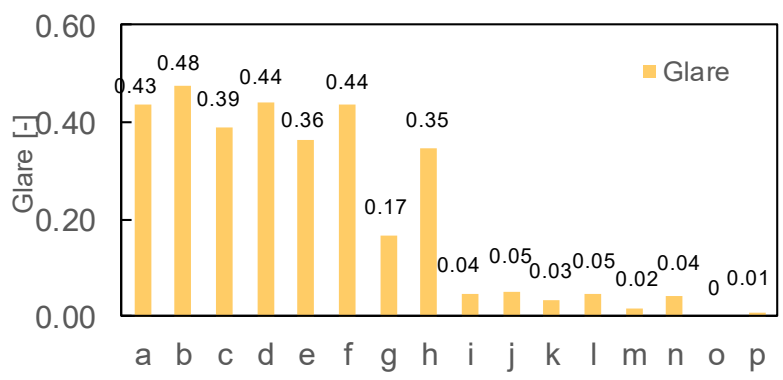

Figure 12 - Glare

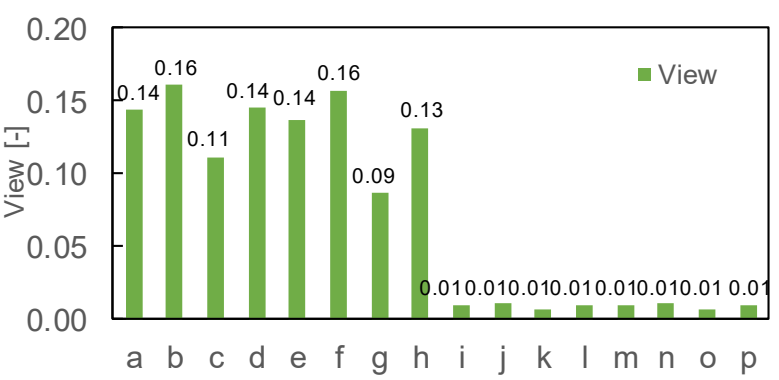

Figure 13 - View

As the blind angle deepened, the vertical louver angle deepened, the width increased, and the spacing narrowed, air conditioning and lighting energy usage was found to increase. As the simulation was based upon the climate in Tokyo (Hyakuri), outside temperatures were low in the winter, and a large percentage of energy usage was air conditioning (heat). Air conditioning energy usage (cooling) tended to increase as vertical louver width narrowed and as the spacing increased; however, blind angle and exterior louver angle did not appear to have a significant effect. Air conditioning energy usage (heat) tended to increase as the blind angle deepened, vertical louver angle deepened, width increased, and spacing narrowed. Lighting energy usage 
tended to increase as the blind angle deepened, vertical louver width increased, and spacing narrowed, while vertical louver angle had little impact.

Glare and view tended to grow larger, the shallower the blind angle became, and those properties grew somewhat larger as the vertical louvers width narrowed, spacing increased, and blind angle grew shallower.

\subsection{Multi-Objective Optimization Simulation Results}

A multi-objective optimization calculation for energy, glare, and view was conducted using the parametric tool Grasshopper and the multi-objective optimization plug-in software OCTOPUS. The following conditions were set for the genetic algorithm: 12 samples in the first generation, 5 generations, a mutation rate of 0.1 , and a crossover rate of 0.8 . The algorithm HypE was selected. The results are shown in Figure 14. Energy, glare, and view were represented as axes in the Pareto solution. Glare and view shrank as air conditioning/lighting energy usage increased, and glare increased as view increased, which is consistent with the parametric simulation.

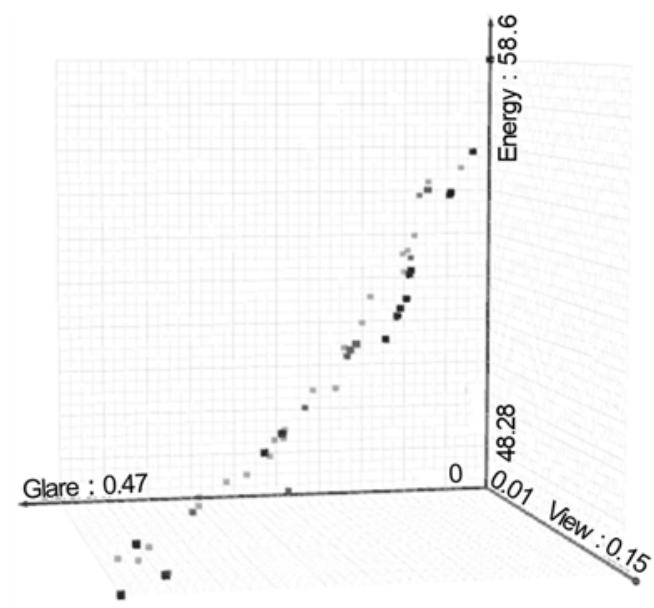

Figure 14 - Pareto optimal solution (Tokyo Hyakuri)

\section{Summary}

We used a Meta_Simulation platform that combined Radiance and NewHASP to evaluate the lighting and air conditioning energy of exterior and interior sun shading devices. We confirmed the behaviour of basic parameters by combining glare and view evaluations from Radiance and using the graphical algorithm editor Grasshopper to calculate air conditioning/lighting energy, glare, and view. By utilizing the plug-in software OCTOPUS, we evaluated air conditioning/lighting energy usage, glare, and view based on four variables of exterior and interior sun shading devices and the optimal solution for Tokyo (Hyakuri) was confirmed.

For glare, the vertical illuminance of the viewpoint was not high in the building targeted by our simulation, and because no cases exceeded the allowable simplified DGP value of 0.35 , the threshold was lowered to evaluate glare.

Under the European Standard, view is evaluated based upon the horizontal angle of the window, the distance to adjacent buildings, and the number of layers for sky, landscape, and ground that can be seen. We used a simple evaluation based upon the ratio of sky that could be seen from a sample point, but it is also possible to incorporate a simulation model using evaluations that follow the European Standard.

We conducted a multi-objective optimization calculation for the annual fixed angle of vertical louvers and of blinds typically used in the sun shading devices. In the future, we plan to apply optimization calculations to complex sun shading devices such as slat cut-off angle controls for blinds, moveable or curved surfaces for exterior sun shading. 


\section{Notes}

Note 1) Radiance calculation parameters.

Table A.1 - Radiance parameter settings

\begin{tabular}{|l|c|c|c|c|c|c|c|c|c|c|c|c|c|}
\hline & ab & aa & ar & as & ad & Iw & dc & dt & dj & st & ss & e & c \\
\hline $\begin{array}{l}\text { Direct radiation } \\
\text { Three-phase method }\end{array}$ & 0 & 0.15 & 512 & 32768 & 65536 & $1.52 \mathrm{e}-5$ & 1 & 0 & 0 & 1 & 0 & MF:6 & - \\
\hline $\begin{array}{l}\text { Diffuse radiation } \\
\text { Three-phase method }\end{array}$ & 0 & 0.15 & 512 & 32768 & 65536 & $1.52 \mathrm{e}-5$ & - & - & - & - & - & MF:1 & 1000 \\
\hline $\begin{array}{l}\text { Dimming level } \\
\text { Daylight Coefficient }\end{array}$ & 1 & 0.15 & 512 & 32768 & 65536 & $1.52 \mathrm{e}-5$ & - & - & - & - & - & MF:1 & - \\
\hline $\begin{array}{l}\text { Glare } \\
\text { Daylight Coefficient }\end{array}$ & 6 & 0.15 & 512 & 256 & 512 & - & - & - & - & - & - & - & - \\
\hline
\end{tabular}

\section{References}

\section{EUROPEAN COMMITTEE FOR STANDARDIZATION. 2019. Daylight in buildings; English version EN} 17037:2018, 2019.3

Architectural Institute of Japan. 2018. Architectural Institute of Japan Environmental Standards AIJESL0003-2018 Standards for Daylighting. (in Japanese)

Architectural Institute of Japan. 2015. Building Equipment Design Standards 2015 Edition. Ministry of Land, Infrastructure, Transport and Tourism Minister's Secretariat Government Office Administration Department, Facilities and Environment Division, Public Architectural Institute of Japan, pp. 428

ATZERI, A., CAPPELLETTI, F., GASPARELLA, A. 2014. Internal Versus External Shading Devices Performance in Office Buildings. Energy Procedia, 45, 463-472.

CHUTARAT, A., Norford, L.K. (2002). A New Design Process Using an Inverse Method: A Genetic Algorithm for Daylighting Design. J. Archit. Plan. Res. Study, 1.

EnergyPlus. Weather data. https://energyplus.net/weather (accessed 2019.3.30).

Food4rhino. OCTOPUS. https://www.food4rhino.com/app/octopus (accessed 2019.3.30).

Grasshopper. Grasshopper algorithmic modeling for Rhino. https://www.grasshopper3d.com/ (accessed 2019.3.30).

LEE, E.S., GEISLER-MORODER, D., WARD G. 2018. Modeling the direct sun component in buildings using matrix algebraic approaches: Methods and validation. Solar Energy, 160, 380-395.

MANZAN, M., PINTO, F. 2009. Genetic Optimization of External Shading Devices. Proc. BS2009, 11th International IBPSA Conference, Glasgow, Scotland, pp.180-187.

NAGAI, T., OHGA, H. 2004. Features and User's Guide of New HASP/ACLD- $\beta$. Proc. SHASE Symp. The Present and the Future of Software for Thermal Load and HVAC, SHASE.

OHGA, H. 2016. NewHASP-Based Meta-Simulation Part 1 Basic Design of NewHASP-Based MetaSimulation. Summaries of Technical Papers of Annual Meeting, Architectural Institute of Japan, Environmental Engineering-II, pp. 31-32.

OHGA, H., YOSHIZAWA, N., AIZAWA, N. 2017a. NewHASP-Based Meta-Simulation Part 4 Coupled Meta-Simulation Model of Daylight Harvesting System \& Multi-Split Air-Conditioning System. Techn. Paper Ann. Meet., 5, H-20.

OHGA, H., YOSHIZAWA, N., OHKI, C., AIZAWA, N. 2017b. NewHASP-Based Meta-Simulation Part 3 Basic Meta-Simulation of Lighting. Summaries of Technical Papers of Annual Meeting, Architectural Institute of Japan, Environmental Engineering-II, pp. 1351-1354.

OHKI, C., OKAMOTO, T., OHGA, H., YOSHIZAWA, N. 2018. Energy Performance Evaluation of Outside Sun Shadings Using Radiance and NewHASP. J. Environ. Eng., 83(753), 861-870. (in Japanese) 
OHKI, C., YOSHIZAWA, N., OHGA, H., AIZAWA, N. 2017. Annual environmental performance evaluation of light and heat in daylight harvesting systems. Summaries of Technical Papers of Annual Meeting, Architectural Institute of Japan, Environmental Engineering-I, 439-442.

Radiance. https://www.radiance-online.org/about/main.html

WIENOLD, J. 2009. Dynamic Daylight Glare Evaluation. Proc. BS2009, 11th International IBPSA Conference, Glasgow, Scotland, pp. 944-951.

YOSHIZAWA, N., MIKI, Y., YAMAGUCHI, H., TAMURA, H. 2018. Systematic Evaluation on Daylight Harvesting Energy-Saving Effects in Offices. J. Environ. Eng., 83(747), 425-434. (in Japanese) 